\title{
Dos cartas de Pedro Henríquez Ureña
}

Honrado por la benévola invitación de mi estimado amigo Revista Iberoamericana, para colaborar en el homenaje a la memoria de Pedro Henríquez Ureña, con algún recuerdo personal o el envío de alguna carta autógrafa del nunca bastante llorado amigo mío, - tan querido como admirado-, he tenido la fortuna de hallar entre los pocos papeles salvados del naufragio de la guerra de España, dos cartas, las únicas que conservo hoy de la abundante correspondencia que con él sostuve. Las demás, las cuales guardaba avaramente en Madrid, se han perdido.

Mi amistad con los hermanos Henríquez Ureña data de muy atrás. Empezó con Max, en La Habana, allá por 1908; continuó con Pedro, en Nueva York, alrededor de 1914, y conocí a Camila, en Nueva York también, años más tarde. Pedro y yo éramos asiduos lectores en la Biblioteca de la Sociedad Hispánica de América, a donde nos llevaban nuestras comunes aficiones. Por cierto que una de las suyas, no muy conocida entre la multitud de sus trabajos de investigación, era la bibliografía. Precisamente una de las cartas que reproduzco es un testimonio de esa dedicación. Recuerdo haberle visto inclinado sobre los volúmenes de Nicolás Antonio, tan poco consultados por los investigadores modernos, quizá, en el caso de algunos, por hallarse la obra del gran bibliógrafo redactada en latín.

Sabido es que su estudio se encuentra muy abandonado en nuestros días. Para Henríquez Ureña, humanista hasta la médula, era obra de consulta constante y fructuosa. 
Las dos cartas copiadas a continuación me fueron dirigidas en 1932 y 1933, época en que Henríquez Ureña desempeñaba el alto puesto de Superintendente General de Enseñanza de la República de Santo Domingo, según reza el membrete. Trata en ellas su autor de asuntos relacionados con el Centro de Estudios Históricos de Madrid y con la Revista de Filología Española, cuyas secretarías estaban a mi cargo. Se refiere a artículos, reseñas, notas y bibliografía que enviaba como colaboración para la revista. Habla de las pruebas de la $2^{\text {a }}$ edición corregida y adicionada de su famoso libro La versificación irregular en la poesía castellana. $\mathrm{Y}$ da la noticia, en la primera carta, de que está preparando una "Bibliografía general de la literatura hispanoamericana", la cual se ha visto forzado a suspender por no encontrar colaborador. Insinúa luego que quizá yo podría ser el colaborador y acaba por hacerme el ofrecimiento, que mucho me honraba, de trabajar con él en la empresa. En la segunda carta, vuelve sobre este tema, y me propone remitirme todas sus papeletas a fin de que yo las completara. En aquel entonces, me hallaba abrumado de trabajo, y no pude aceptar uno más, a pesar de que tanto me satisfacía y cautivaba. Henríquez Ureña pensó enviar al archivo de la Revista de Folologra gradualmente, lo que llevaba hecho "para que no se extravíe al fin". Estas son sus palabras; pero no pudo realizar su intento. Con anterioridad venía remitiéndonos algunas papeletas de bibliografía corriente hispanoamericana que se publicaban en la revista, mas nunca se recibió bibliografía retrospectiva. ¿Dónde estarán depositadas actualmente aquellas fichas?

En la segunda carta hace referencia a un trabajo de José María de Cossío, publicado en la Revista de Filología (1932, XIX, 283-287), sobre El modelo estrófico de los "layes, decires y canciones" de Rubén Dario, en el que coincide con la tesis $\mathrm{y}$ detalles $\mathrm{y}$, por lo tanto, los corrobora, de un artículo anterior de Henríquez Ureña, Rubén Darío y el siglo $X V$, (Revue Hispanique, 1920, L, 324-327). Henríquez Ureña adjunta una nota, que se insertó en la $R F E$ (1932, XIX, 421-422), en la que hace constar dicha coincidencia y aprovecha la oportunidad para añadir ciertas observaciones acerca del casticismo de Darío, "para oponerse a la opinión vulgar de que Darío 
sólo había leído literatura francesa". "La verdad —afirmaes que en su adolescencia leyó asiduamente la literatura española". Agrega varias citas, entre ellas la del estudio poco conocido de Jesús Zavala, hecho bajo la dirección de Henríquez Ureña en el Seminario de Literatura Castellana de la Universidad Nacional de México, sobre Rubén Darío y la Literatura española, impreso en la Revista de Revistas, México, 1923. Y asimismo el libro de Torres Rioseco, Rubén Darío: casticismo y americanismo, Harvard University, 1931.

Por mi conocimiento personal y por las cartas de Pedro Henríquez Ureña, arrancado a nuestro afecto y admiración por inesperada y prematura muerte, pude apreciar sus altísimas cualidades de ciudadano y maestro de todo un Continente.

HOMERO SERÍS

Centro de Estudios Hispánicos, Syracuse University

He aquí la copia de sus dos cartas escritas de su puño y letra, con su clara y bella escritura; según podrá observarse por el facsímil de la primera que ocupa sólo una página:

El Superintendente General de Enseñanza

Santo Domingo,

29 de noviembre, 1932.

Mi querido amigo:

Contesto a su atenta carta, avisándole que ya estoy haciendo la reseña de la bibliografía dominicana de Waxman, trabajo defectuoso. Mi blibliografía general de la literatura hispanoamericana está suspendida porque nunca encontré colaborador y aquí hay pocos medios para continuarla. He pensado enviar a la Revista de Filología Española, al archivo, gradualmente, lo que llevo hecho, para que no se extravíe al fin. ¿Quizás usted podría ser el colaborador? Se trata de bibliografía general, no del tipo preciso y minucioso que usted domina; pero tal vez le interese. Usted dirá. 
52

REVISTA I B E R O A M E I C A N A

Il Suprintentente Gereral of Experiztote
Santo Boming,

gig de roniculus 32

th querib arifo: Contesto a en stente cut arisánolo que yo estry haciondo le reseñ a 2 bibligrfí dominicam de Waxmaw, trabir defestums.

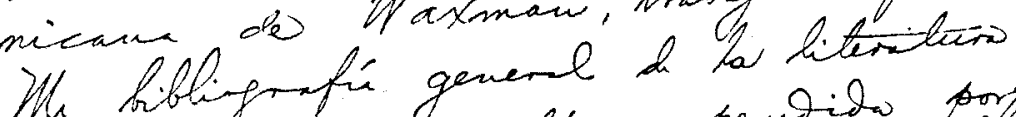
hicparmamenicans esti' ouspendita, Aorpe numea excout tó coliborador y agu'

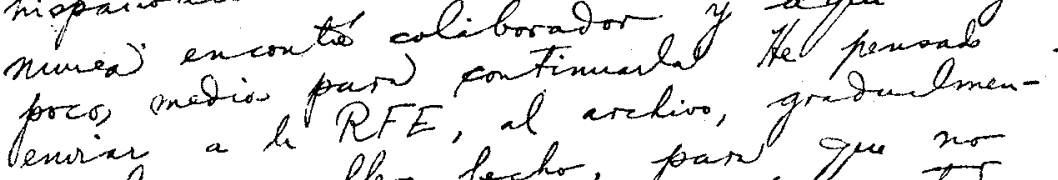

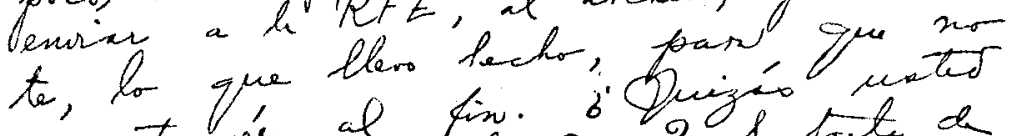
s extrane al lim. ó ? trite de

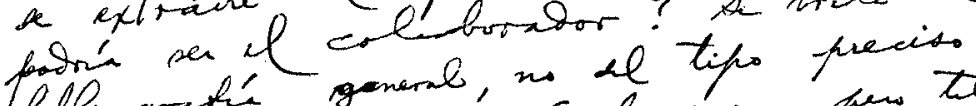

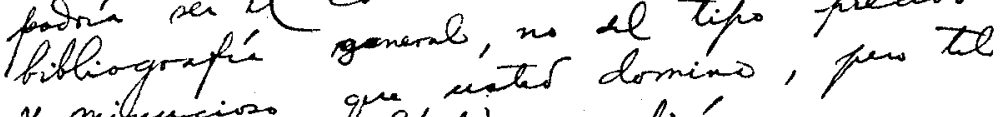
y mimucioso que cuater domint

Remit' you mis iltinns punebs de

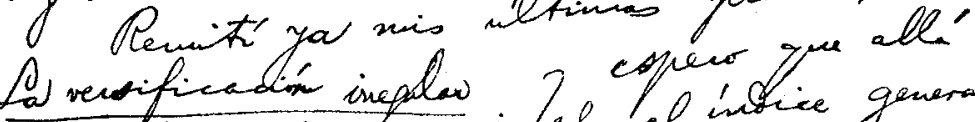

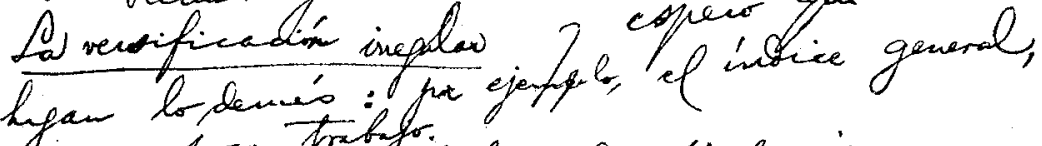

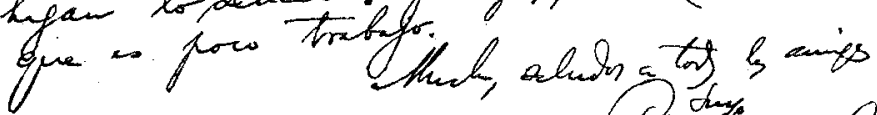

Sery

Carta manuscrita del Dr. Pedro Henriquez Ureña dirigida al Dr. Homero Serís. 
Remití ya mis últimas pruebas de La versificación irregular y espero que allá hagan lo demás: por ejemplo, el índice general, que es poco trabajo.

Muchos saludos a todos los amigos.

Suyo.

\section{PEDRO HENRIQUEZ URENA.}

\section{II}

El Superintendente General de Enseñanza

Santo Domingo,

8 de marzo de 1933.

Sr. D. Homero Serís

Madrid.

Mi querido amigo:

Acabo de recibir sus amables letras de 12 de febrero. Días atrás recibí la Revista, y al leer el trabajo de Cossío escribí la nota que va adjunta. Pude haber sido más breve, pero quise aprovechar la ocasión para hacer observaciones sobre el casticismo de Darío y recordar el trabajo, poco conocido, de Zavala. Quise agregar algún adjetivo en elogio de Cossío, pero, como él dice lo mismo que yo, temí que, al elogiarlo, pareciera yo elogiar mi propio trabajo. Si ustedes lo creen oportuno, puede agregársele algún calificativo.

Supongo que ya estará lista La versificación irregular. Los ejemplares que se me destinen como autor, quiero que los reserven allá hasta nueva indicación que yo le haga. Mientras tanto, pueden enviárseme tres ejemplares.

No he recibido respuesta de usted sobre la proposición que le hice para que colaborara conmigo en la bibliografía general de la literatura hispanoamericana. Yo le enviaría todas mis tarjetas $\mathrm{y}$ usted las completaría con otras. El trabajo sería lento, pero creo que sólo puede hacerse bien en el Centro.

Con recuerdo para todos los amigos, quedo suyo. 
